\section{SITUACIÓN DEL REGIMEN DE CARRERA ADMINISTRATIVA EN COLOMBIA}

Efrén González Rodríguez*

Fecha de Recepción: 22 de Abril de 2010

Fecha de Aceptación: 30 de Abril de 2010

Artículo de Reflexión

\section{Resumen}

Este trabajo es un análisis crítico sobre la situación del régimen de Carrera Administrativa en Colombia, relacionando aspectos jurídicos, históricos y políticos. Señala la necesidad de establecer normatividad y procedimientos garantes del sistema de mérito, como opuesto al clientelismo y el favoritismo, para garantizar el derecho constitucional de acceder a cargos y funciones públicos, así como crear una administración eficiente, eficaz y moral. Igualmente, en el se denuncia cómo el Congreso de la República aprobó un proyecto de Acto Legislativo, sobre inscripción extraordinaria a empleados en provisionalidad, que privilegiaba clientelismo, amiguismo y nepotismo, contradiciendo la Carta Política imperativa sobre el sistema de mérito.

\section{Palabras Clave}

Carrera Administrativa, Igualdad, Eficacia, Eficiencia y Moralidad.

\footnotetext{
Docente Facultad de Derecho Universidad Libre. Magíster en Derecho Administrativo. Universidad Libre. Especialista en Derecho Laboral, Administrativo y Derechos Humanos de la Universidad Externado de Colombia. Correo electrónico: efrengonzalezr@ yahoo.com
}

\section{SITUATION OF THE REGIMEN \\ CAREER ADMINISTRATIVE IN COLOMBIA}

\begin{abstract}
This work is a critical analysis about the situation of the regimen career administrative in Colombia, involving legal, historical and political aspects. It notes the need to establish a regulatory system to ensure merit, as opposed to patronage and favoritism, in order to guarantee the constitutional right of access to public positions and functions, for the purpose of creating an efficient administration, effective and moral. Also, it is denounce how the Congress approved a bill on special registration or automatic temporary employees favoring patronage, cronyism and nepotism, contradicting the very Constitution that mandates that all jobs are career.
\end{abstract}

\section{Keywords}

Administrative Career, Equality, Effectiveness, Efficiency and Morality.

\section{INTRODUCCIÓN}

Este escrito sobre el régimen de Carrera Administrativa nace de las inquietudes surgidas de la experiencia propia en la gestión administrativa y en la cátedra universitaria, en búsqueda de alcanzar los principios finalísticos de la función pública como eficacia, moralidad, imparcialidad y publicidad.

Debe entenderse que si el Estado Colombiano fija un sistema asegurador del mérito como eje central de la vinculación, permanencia y ascenso en el empleo público, ampliado a ciertos cargos de dirección, avanzará con prontitud hacia el logro de la eficacia, eficiencia y progreso en la prestación de los servicios públicos y e logro de los cometidos estatales. 
Así, problemas como la corrupción, la ineficiencia y el desgreño administrativos, perturbadores de nuestro orden jurídico institucional, podrán erradicarse con voluntad política sobre erradicación de prácticas parcializadas o inmorales sobre el ingreso al servicio público, en especial en cargos de alta gerencia o de dirección intermedia, por lo que se hace necesario un sistema de meritocracia, que amplíe su cobertura y evalúe de manera constante los cargos de todos los niveles de la administración.

La Corte Constitucional al declarar la inexequibilidad del Acto Legislativo 01 de 2008, que buscaba regresar el viejo sistema de inscribir automáticamente a los empleados en provisionalidad sin concurso de méritos, por el simple paso del tiempo, consideró que tal norma sustituía un eje definitorio de la identidad de la Carta Política como lo es el mérito, eje central del ingreso a la función pública, pues como lo señala el Artículo 125 Constitucional todos los empleos del Estado son de carrera y los que la ley no haya fijado, el sistema de ingreso debe hacerse mediante concurso. Así, cuando se sustituye un eje definitorio de la Constitución, la competencia radica en el constituyente primario y no en el Congreso de la República, que obra como constituyente derivado, el cual solo tiene facultades de reformar la Carta y no de sustituirla.

Este ensayo busca ser instrumento eficaz en defensa de los principios y derechos propios de la relación laboral de derecho público, consagrados en la Constitución Política, los Tratados Internacionales O. I. T. sobre derechos mínimos fundamentales del Trabajo y la jurisprudencia de la Corte Constitucional como tribunal de cierre de todas las jurisdicciones, en defensa de derechos fundamentales.

Por lo anterior, estas reflexiones seguramente serán objeto del análisis crítico de los académicos, los servidores del Estado y los profesionales del Derecho y la administración pública.

\section{Concepto}

La carrera administrativa es un sistema técnico sobre la administración de personal en el Estado, que tiene consagración constitucional y legal, con el objeto de ofrecer igualdad de oportunidades para acceder a la función pública, lograr la eficiencia de la administración, el buen servicio a la sociedad y la profesionalización o estabilidad en los empleos.

La carrera administrativa es un sistema de administración de personal que regula deberes y derechos, de la administración y del empleado, en el cual el ingreso y el ascenso están determinados por la capacidad o el mérito, sin consideraciones de raza, religión, sexo, filiación política o cualquier otra circunstancia que incida en los procesos de selección.

El principio que rige la carrera administrativa es el de eunomía o ley del mejor, el cual garantiza la eficacia y la eficiencia de la administración, por lo que el sistema de carrera es contrario al clientelismo corruptor ${ }^{1}$.

Con el sistema de carrera se busca lograr no solo la eficacia sino también la honestidad en el desempeño de cargos públicos, para lo cual el Estado debe contar con servidores cuya experiencia, conocimiento y dedicación garanticen con sus resultados su verdadera aptitud para atender las altas responsabilidades confiadas a los entes públicos, a partir del concepto según el cual el Estado Social de Derecho exige la aplicación de criterios de excelencia en la administración pública.

\section{Antecedentes Históricos}

En un Estado Social de Derecho, los servidores además de representar al Estado cumplen una importante función social en el ejercicio o con

VILLEGAS ARBELAEZ, Jairo. Derecho Administrati-

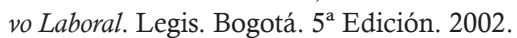


ocasión de sus funciones. "Las raíces históricas de la carrera debemos explicarlas en el contexto de la separación de la sociedad del Estado (hacia el siglo XVIII), y en la aparición de la administración publica para mantener la relación entre los dos entes"2.

Desde la Declaración Universal de los Derechos del Hombre y del Ciudadano del 4 de agosto de 1789, puede registrarse como antecedente normativo del sistema el Artículo sexto señala que todos los ciudadanos siendo iguales, son igualmente admisibles a todas las dignidades, puestos y empleos, sin otra distinción que la de sus talentos y virtudes.

En la Declaración Universal de los Derechos Humanos de la ONU en 1948, aparece consagrado en los numerales 1 y 2 del Artículo 21 el derecho de toda personas a participar directamente en el gobierno de su país y a acceder, en condiciones de igualdad, a las funciones públicas.

En Colombia las Constituciones Políticas guardaron silencio sobre el tema y solamente mediante la reforma plebiscitaria de 1957 el tema se elevó a canon constitucional, a pesar que se había expedido la Ley 165 de 1938, la cual no tuvo eficacia en su aplicación.

En nuestro país el tema ha encontrado múltiples tropiezos desde sus inicios; hoy en día su desarrollo no se ha perfeccionado, por falta de voluntad política. Existen grupos interesados en que la anarquía y el clientelismo continúen reinando.

"Nuestra cultura para la vinculación de personal a la Administración Publica se basa en la palanca, en la recomendación politica, en el amiguismo; no en la selección racional y objetiva

2 GONZÁlEZ GARCÍA, Emilio. "La Carrera Administrativa en la modernización estatal". En: Revista Administración y Desarrollo. Escuela Superior de Administración Pública. No. 42. $2^{\circ}$ Semestre de 2004. Bogotá. p. 35 de los aspirantes teniendo en cuenta el criterio del merito, del que mas conoce, del que mas sabe. Esta es una costumbre inveterada en las organizaciones publicas que ni las leyes, ni los decretos ni la misma Constitución Politica ha podido erradicar, simplemente porque la cultura, es decir la manera de hacer las cosas, no se puede cambiar a través de una norma y en la mayoría de los casos no cumplen la función de tecnificar y modernizar los funcionarios de las organizaciones, dejando si a la deriva el soporte de desarrollo que la carrera administrativa requiere" ${ }^{3}$.

Desde sus inicios y hasta el presente, el sistema de carrera en Colombia ha tropezado con problemas de diferente índole. En algunas ocasiones con dificultades de tipo presupuestal, por nuestra misma cultura, con falta de voluntad política del alto gobierno y adicionalmente con inconsistencias desde el punto de vista legal y constitucional.

En Colombia el tema de carrera administrativa ha tenido desarrollo normativo desde 1938, con la Ley 165, la cual consagró la estabilidad laboral de los servidores escalafonados en ella. Además, consagró derechos como el ascenso, el reconocimiento económico por vacaciones, cesantías, indemnizaciones por accidente de trabajo, seguro de vida, auxilio por enfermedad, pensión de jubilación; creó el Consejo Nacional de Administración y Disciplina que elaboraba el escalafón de los empleados.

Este primer esfuerzo fracasó debido a la escasez de recursos presupuestales, la ausencia de personal idóneo, a que los jefes de la Administración no estaban preparados para asumir el reto y los funcionarios no fueron proactivos y asumieron una posición cómoda, escondiéndose en la inamovilidad conferida por la ley.

3 COLLAZOS ÁLVAREZ, Augusto. "¿Por que no funciona elsistema deCarrera Administrativa?”.En:Revista Administración y Desarrollo. Escuela Superior de Administración Pública. No. 42. $2^{\circ}$ Semestre de 2004. Bogotá. p. 78. 
Además, el informe rendido por la misión Currie fue completamente desalentador sobre la experiencia de la carrera administrativa entre 1938 y 1952. Después de doce años de experiencia practica sobre la carera administrativa, el concepto de todos los sectores, empleados, supervisores, sindicatos, altos funcionario y el público en general fue unánime en cuanto a que la carrera administrativa no logró su finalidad y se hizo inoperante.

"De un total de cerca de 50.000 empleados con que contaba el gobierno, menos de 1500 habian ingresado a la carrera administrativa desde cuando esta se estableció, y de ese número, solo unos 100 figuraban como empleados al servicio del gobierno. Mas aún, del reducido numero de empleados que han sido admitidos en carrera, solo un total insignificante, 42, ingresaron con base en exámenes. Los demás ingresaron debido a una serie de dispensas de los funcionarios ejecutivo, basadas especialmente en la terminación de dos años de servicio $y$ en un certificado de buena conducta. Se comprobó igualmente que a menudo las disposiciones protegían al empleado contra las destituciones inspiradas en razones politicas, y se habian usado indebidamente con el objeto de mantener en sus cargos a muchos empleados deficientes e incompetentes, lo cual dio como resultado en algunos sectores que el hecho de pertenecer a la carrera administrativa fuera en realidad mirado mas bien como sospecha o desconfianza antes que como una prueba de competencia y meritos individuales" 4 .

Así las cosas, el panorama jurídico político de la carrera administrativa en Colombia del Siglo Veinte era casi nulo y lo que imperaba era el clientelismo, cimentado en el sectarismo partidista y el favoritismo personal.

4 GONZÁLEZ SALAS, Edgar. "La Carrera Administrativa: experiencias y perspectivas". En: Revista Administración y Desarrollo. Escuela Superior de Administración Pública. No. 42. $2^{\circ}$ Semestre de 2004. Bogotá. p. 7.
Fue hasta 1957, cuando los partidos hegemónicos lograron ponerse de acuerdo y diseñar e implementar un sistema de carrera. En los acuerdos de Benidorm y Sitges, suscritos en 1957 por Alberto Lleras y Laureano Gómez que dieron origen al acto plebiscitario de 1957 se determinó limitar la facultad omnímoda del presidente en la elección y despido de los funcionarios del gobierno creando una carrera respetable y seria de especialistas en el manejo de los negocios públicos, toda vez que los propios empleados o aspirantes eran quienes promovían la violencia para promover sus cargos o la desataban para adquirirlos ${ }^{5}$.

Con el plebiscito de 1957 se elevó la carrera administrativa al plano constitucional, en la reforma de 1958, que instituyó que en ningún caso la filiación política de los ciudadanos podría determinar su nombramiento para un empleo o cargo público de carrera administrativa, o su destitución o promoción. Con la expedición de la Ley 19 de 1958, se crearon, entre otros, el Departamento Administrativo del Servicio Civil, la Escuela de Administración Pública, la Sala de Consulta y Servicio Civil del Consejo de Estado, que dieron un sentido más técnico a las obligaciones del Estado con respecto a la administración de personal.

El país replanteó el sistema de nombramiento y provisión de empleos, en el sentido que la facultad constitucional del presidente para nombrar y remover funcionarios públicos debería ser restringida a los cargos que esencialmente sean políticos de confianza o de agencia presidencial, y para los empleos de la rama ejecutiva que no cumplan estas características se restringirá la facultad nominadora ${ }^{6}$.

5 VILLEGAS ARBELAEZ, Jairo. Derecho Administrativo Laboral. Ob. Cit.

6 YOUNES MORENO, Diego. Derecho Administrativo Laboral. Temis. Bogotá. 2005. p. 200. 
Posteriormente, se expidió el Decreto-Ley 1732 de 1960 el cual clasifica los empleos en 2 categorías: libre nombramiento y de carrera, estableciendo como método de elección de funcionarios la selección técnica de personal basada en la igualdad y merito personal. "Su ejecución fue parcial en el nivel nacional y su extensión al nivel territorial fue marginal" 7 .

Esto sucedió, pues hasta el momento se consideraba que el nivel territorial no tenía la misma importancia que el nacional, ni en materia de funciones o de asignación presupuestal. " $\mathrm{La}$ aplicación de la carrera bajo este estatuto en el orden nacional fue muy tímida, en tanto que en el orden territorial fue imposible por los apetitos burocráticos de los grupos politicos que exigían a los nominadores la inclusión de adeptos a la nomina oficial"8.

Posteriormente, con la administración de Carlos Lleras Restrepo, se produjo la reforma administrativa, con la expedición del Decreto 2400 de 1968, cuyos principales aportes fueron descentralizar la selección a las unidades de personal de cada organismo, pasar de un estatuto para funcionarios de carrera a un reglamento de administración de personal, y volvió a marginarse el nivel territorial pues se interpretó que la aplicación de este estatuto se restringía únicamente a nivel nacional.

"La importancia institucional del nivel territorial se encontraba socavada para entonces. Los departamentos y municipios habian entrado desde los años 30 en un proceso de languidecimiento paulatino tanto por la representación de sus ingresos fiscales con respecto al PIB, como en cuanto a su participación en el conjunto de los ingresos tributarios nacionales. La mayor parte del gasto publico se realizaba a instancias

GONZÁLEZ SALAS, Edgar. "La Carrera Administrativa: experiencias y perspectivas". Ob. Cit. p. 9.

8 GONZÁLEZ GARCÍA, Emilio. "La Carrera Administrativa en la modernización estatal". Ob. Cit. p. 33. del nivel nacional y en especial de su robusta y creciente institucionalidad paraestatal"'.

Aunque existía el decreto y era apto para su aplicación nacional, al mismo tiempo convivían intereses diametralmente opuestos, pues el fenómeno del clientelismo se encontraba arraigado bajo la piel de los encargados de implementar la política en el momento; prueba de esto es que la reglamentación de la carrera administrativa fue hasta 1973, momento en el cual su aplicación se convirtió en interina bajo el amparo del Estado de Sitio. 10 años después se decretan vigentes nuevamente, pero con la condición que su implementación fuera realizada de manera gradual, es decir, la carrera administrativa se convirtió en una bola de nieve para la administración publica por la cantidad de cargos provisionalidades creados.

Posteriormente, aparece en escena la Ley 61 de 1987 la cual determina los empleos de libre nombramiento y remoción. Y por un criterio residual "son de carrera los demás empleos no señalados como de libre nombramiento y remoción", regula además figuras como: el retiro, la insubsistencia, la Carrera Diplomática y Consular.

Finalmente, con la promulgación de la Constitución Nacional y los desarrollos de la última década del siglo pasado:

"La Ley 27 de 1992; la Ley 200 de 1995, por la cual se adopta el Código Disciplinario único y la Ley 443 de 1998 sobre normas relativas a la carrera administrativa $y$ sus decretos complementarios: el Decreto 1567, crea el sistema nacional de capacitación y sistema de estímulos para empleados del Estado; el Decreto 1568, sobre el régimen procedimental para actuaciones administrativas entre autoridades del Sistema Nacional de Carrera Administrativa y de la Función Publica, Este ultimo modificado por el

9 GONZÁLEZ SALAS, Edgar. "La Carrera Administrativa: experiencias y perspectivas". Ob. Cit. p. 10. 
Decreto 2504 de 1998. En diciembre de 1998 se expide la Ley 489 o estatuto básico de organización y funcionamiento de la administración publica y en agosto de 1999 el Decreto 1444 reestructura el Departamento Administrativo de la Función Publica y le asigna la responsabilidad de fijar politicas en gestión del talento humano en torno de todas sus practicas administrativas"10.

E1 periodo de vigencia de esta Ley fue tormentoso para la administración pública, pues por una parte la Comisión de Servicio Civil no cumplía a cabalidad con sus funciones, la mayoría de las veces por el desinterés o la falta de tiempo de sus miembros, quienes estaban conformados de una manera tan heterogénea que les hacia muy difícil cumplir a cabalidad con tan altas funciones. Por otra parte, el gobierno inicio una campaña para satanizar a la carrera, y en especial su inamovilidad, pues constituía un claro obstáculo para la modernización del Estado, quien tenia en sus planes afectar la planta de personal de la Administración; aunado a estos factores, los concursos se encontraban amañados, es decir, el clientelismo aun reinante había refinado sus métodos. En vista de la situación la Corte Constitucional "dejó sentado como principio que las entrevistas, fueron finalmente limitadas en cuanto a la representatividad de su valor en el puntaje definitivo"11.

Reformó la Comisión Nacional del Servicio Civil, los concursos, los criterios de objetividad y mensurabilidad para las pruebas, redefinió los empleos, estableció criterios para valorar el desempeño, puso límites a la supresión de empleos, estableció el concurso de ascenso, el derecho preferente de un empleado a quien se le hubiese suprimido el empleo.

10 Ver: http://cuadernosadministracion.javeriana.edu. co/pdfs/3_28.pdf.

11 GONZÁLEZ SALAS, Edgar. "La Carrera Administrativa: experiencias y perspectivas". Ob. Cit. p. 16.
Es importante destacar que la Comisión Nacional de Servicio Civil es de origen Constitucional, y según ella goza de autonomía, por lo que la declaratoria de inexequibilidad de algunas disposiciones de la Ley 443 de 1998, sobre su conformación quebraron la aplicación, pues no era ajustado a la Carta que la Comisión no tuviese carácter único nacional y estuviese integrada en su mayoría por el Ejecutivo $^{12}$.

Actualmente, el régimen de carrera administrativa se encuentra regulado en la Ley 909 de 2004 que buscó ajustar las falencias señaladas, con fundamento en la jurisprudencia desarrollada por la Corte Constitucional, como el otorgamiento de plena autonomía a la Comisión Nacional del Servicio Civil, creando los acuerdos de gestión entre los nominadores y los cargos de gerencia pública, así como la posibilidad de organizar concursos de meritocracia para algunos cargos de libre nombramiento y remoción; igualmente, determinó un término máximo de seis años para comisionar a servidores de carrera en cargos de libre nombramiento, también consagró el respeto a los derechos de maternidad, embarazo, discapacitados y desplazados, entre otros; además, fijó los procedimientos para las distintas etapas de los concursos públicos de méritos, a partir de la convocatoria y expresó las causales de retiro de los servidores de carrera.

\section{Definición Constitucional}

El Artículo 125 de la Carta Política determinó que todos los empleos en los órganos y entidades del Estado son de carrera, con excepción de los de elección popular (diputados, gobernadores, alcaldes y concejales), los trabajadores oficiales (vinculados a la administración por

12 CORTE CONSTITUCIONAL. Sentencia C - 372 de 1999. M. P. José Gregorio Hernández Galindo. 
contrato de trabajo), los de libre nombramiento y remoción (gerentes públicos) y los demás que determine la ley.

En este sentido, la Carta Política fija como principio que el ingreso y ascenso en los cargos de carrera se hará previo cumplimiento de los méritos de los aspirantes, sin que la filiación política sea el factor determinante para tales cometidos.

También, la Constitución determinó que los funcionarios cuyo sistema de nombramiento no hubiese sido determinado por la Constitución y la ley, serán nombrados por concurso público. Así, se han expedido normas sobre meritocracia para cargos, que sin tener naturaleza de carrera administrativa, su ingreso se efectúa mediante concurso de méritos como la designación de los Directores Regionales entidades del nivel nacional como el SENA, o del I.C.B.F., o Directores Departamentales, Municipales o Distritales de Directores de las E.S.E., o el nombramiento de Alcaldes Locales o miembros del Tribunal de Justicia en el Distrito Capital.

La Carta también determinó las causales del retiro del servicio para los empleos de carrera, a efectos de no permitir discrecionalidad al nominador en esta temática; las causales indicadas son por calificación no satisfactoria en el desempeño del empleo, por violación del régimen disciplinario y por las demás causas que determine la ley. El Artículo 41 de la Ley 909 de 2004, señala expresamente las demás causales de retiro del servicio como la renuncia regularmente aceptada, la muerte, la pensión de jubilación, la destitución, la edad de retiro forzoso, entre otras.

\section{Fines}

Los fines de la carrera administrativa son: la realización de los principios de eficacia y eficiencia en la función pública, procurar la estabilidad en los cargos públicos, erradicar el clientelismo y la inmoralidad en la administración, aplicar los principios de eunomía y excelencia en el desarrollo de las funciones. Así mismo, con este sistema se realiza el principio de igualdad, por cuanto el merecimiento es la base sobre la cual el empleado ingresa, permanece, asciende o se retira del empleo. Además, garantiza el derecho a los ciudadanos de acceder al desempeño de funciones y cargos públicos en igualdad de condiciones u oportunidades.

Se busca que la administración esté conformada por personas aptas desde los puntos de vista de capacitación profesional e idoneidad moral, para que la función que cumplan sea acorde con las finalidades del interés general, lo cual se espera de los empleados que prestan sus servicios al Estado. El elemento objetivo de la eficiencia es el determinante de la estabilidad laboral, por cuanto es su principio de razón suficiente. No se trata de una permanencia en el cargo por razones ajenas a la efectividad de los buenos resultados ${ }^{13}$.

En la exposición de motivos de la Ley 909 de 2004 se establece como finalidad:

"Crear las condiciones institucionales para que se pueda construir un servicio civil de naturaleza profesional y que sea, además, uno de los referentes del programa de renovación del sector público... El principio de mérito no se detiene exclusivamente en los contornos del empleo público de carrera, sino que extiende su radio de acción a los puestos de gerencia pública" ${ }^{14}$.

La ineficiencia y la corrupción como factores perturbadores de nuestro ordenamiento jurídico e institucional tiene fundamento en el carácter parcializado y poco cualificado del ingreso y en el desempeño de quienes prestan sus servicios al Estado, en especial de los funcionarios que

13 CORTE CONSTITUCIONAL. Sentencia C-195 de 1994. M.P. Vladimiro Naranjo Mesa.

14 CONGRESO DE LA REPUBLICA. Gaceta No. 232 de 2003. p. 6 . 
desempeñen labores de dirección, representación y política institucional, por lo cual se hace necesario un sistema obligatorio de meritocracia, incluyendo ciertos cargos de dirección.

En otra oportunidad la Corte dijo:

"El régimen de carrera administrativa, tal como lo concibió el Constituyente de 1991, impulsa la realización plena y eficaz de principios como igualdad e imparcialidad, pues se sustenta en la promoción de un sistema de competencia a partir de los méritos, capacitación y especificas calidades de las personas que aspiran a vincularse a la administración pública; sólo cumpliendo esos objetivos, que se traducen en captar a los mejores y más capaces para el servicio del Estado, éste, está en capacidad de garantizar la defensa del interés general, pues descarta de manera definitiva la inclusión de otros factores de valoración que repugnan a la esencia misma del Estado social de derecho"15.

\section{De los procesos de selección, ingreso y ascenso en los cargos de carrera}

La provisión de los cargos de carrera, así como el ascenso en estos empleos, se efectúa mediante concurso, los cuales son abiertos para todas las personas que acrediten los requisitos exigidos para su desempeño, en cumplimiento de los principios de igualdad y mérito.

Según la Ley 909 de 2004, conforme al Artículo 130 Constitucional, la competencia para adelantar los concursos o procesos de selección corresponde a la Comisión Nacional del Servicio Civil a través de contratos o convenios ínter administrativos, suscritos con universidades públicas o privadas o instituciones de educación superior acreditadas por ella para tal fin. Los costos por la realización de los concursos están a cargo de los presupuestos

15 CORTE CONSTITUCIONAL. Sentencia C-563 de 2000. M. P. Fabio Morón Díaz. de las entidades que requieran la provisión de cargos.

La misma ley establece que la Comisión Nacional de Servicio Civil acredita como entidades idóneas para adelantar los concursos a las universidades públicas y privadas y a las instituciones de educación superior que lo soliciten y demuestren su competencia técnica, experiencia y capacidad logística para tal efecto.

Las etapas del proceso de selección o concurso aparecen definidas en la Ley 909 así:

Convocatoria: Deberá ser suscrita por la Comisión Nacional del Servicio Civil y el jefe de la entidad y organismo, es la norma reguladora de todo concurso y obliga tanto a la administración como a las entidades contratadas para la realización del concurso y a los participantes.

La Corte Constitucional acertadamente declaró inexequible el Artículo 56 de la Ley 909 de 2004, que le reconocía a los provisionales reconocimiento de su experiencia, conocimiento y antigüedad en el cargo, lo cual les generaba privilegios, con relación a las personas que concursaban sin tener vínculo alguna con la entidad, lo que generaba vulneración a los principios constitucionales de igualdad y de acceso a cargos y funciones públicas ${ }^{16}$.

Reclutamiento: Esta etapa tiene como objetivo atraer e inscribir el mayor número de aspirantes que reúnan los requisitos para el desempeño de los empleos objeto del concurso.

Pruebas: Son los instrumentos de selección que tienen como finalidad apreciar la capacidad, idoneidad y adecuación de los aspirantes a los diferentes empleos que se convoquen, así como establecer una clasificación de los candidatos respecto a las calidades requeridas.

16 CORTE CONSTITUCIONAL. Sentencia C - 733 de 2005. M. P. Clara Inés Vargas Hernández. 
La valoración de estos factores se efectuar a través de medios técnicos, los cuales deben responder a criterios de objetividad e imparcialidad.

Las pruebas aplicadas o a utilizarse tienen carácter reservado, solo serán de conocimiento de las personas que indique la Comisión Nacional del Servicio Civil en los procesos de reclamación.

Lista de elegibles: Con los resultados de las pruebas la Comisión Nacional del Servicio Civil o la entidad contratada, elaborará en estricto orden de mérito la lista de elegibles con una vigencia de dos años.

La Corte Constitucional ha expresado que la no inclusión de una persona en la lista de elegibles o la figuración de ésta en un lugar que no corresponde, según las consideraciones precedentes, implica violación de derechos fundamentales, entre otros, a la igualdad, al debido proceso y al trabajo. También, determina que la colocación en dicha lista es apenas un acto preparatorio del nombramiento y, por lo tanto, tan sólo crea una expectativa para ser designado en el empleo ${ }^{17}$.

E1 máximo Tribunal Jurisdiccional considera que es pertinente la interposición de la Acción de Tutela, en razón a que a la oportunidad para proveer los cargos, con arreglo al cumplimiento estricto de las reglas del concurso y el reconocimiento efectivo de las calidades y el mérito de los concursantes, cuando existen controversias entre la administración y los participantes en el concurso, requiere de decisiones rápidas que garanticen en forma oportuna la efectividad de estos derechos ${ }^{18}$.

Además, ha sido insistente en otorgar los derechos a las personas que hayan ocupado

17 CORTE CONSTITUCIONAL. Sentencia T - 720 de 2008. M. P. Jaime Córdoba. T.

18 CORTE CONSTITUCIONAL. Sentencia T - 256 de 1995. M. P. Alejandro Martínez C. el primer puesto en los concursos de méritos. Quien ocupe el primer puesto en el concurso debe ocupar el cargo para el cual concursó. En consecuencia, para la designación de una persona en un determinado cargo, basta que la persona reúna las calidades exigidas por la ley y ocupe el primer puesto del listado de elegibles, siempre que no concurra ninguna causal de inhabilidad o incompatibilidad para el ejercicio del cargo $^{19}$.

Período de prueba: La persona no inscrita en carrera administrativa que haya sido seleccionada por concurso será nombrada en periodo de prueba por el término de seis meses, al final de los cuales le será evaluado el desempeño, de acuerdo con lo previsto en el reglamento.

Aprobado dicho periodo al obtener evaluación satisfactoria del desempeño el empleado deberá ser inscrito en el Registro Público de Carrera Administrativa. De no obtener calificación satisfactoria del periodo de prueba, el nombramiento del empleado será declarado insubsistente.

Inscrito en el escalafón de carrera el empleado adquiere los derechos de carrera los cuales son: la estabilidad laboral, la capacitación permanente, los estímulos por el desempeño sobresaliente, ser comisionado en un cargo de libre nombramiento y remoción y a ser reincorporado o recibir indemnización en caso de supresión del cargo.

El empleado inscrito en el Registro Público de Carrera que supere un concurso será nombrado en periodo de prueba, al final del cual se le actualizará su inscripción si obtiene calificación satisfactoria en la evaluación del desempeño. Mientras se produce la calificación de este periodo, el cargo del cual era titular el

19 CORTE CONSTITUCIONAL. Sentencia SU - 257 de 1999. M. P. José Gregorio Hernández G. 
empleado ascendido, podrá ser provisto por encargo o mediante nombramiento provisional.

En el evento que un servidor inscrito en el escalafón de carrera, no supere el periodo de prueba para un cargo de mayor jerarquía, no pierde sus derechos de carrera sino que regresa al cargo del cual es titular y en el que se encuentra inscrito en carrera.

\section{De la evaluación de desempeño y calificación de los empleados de carrera}

La permanencia en los cargos de carrera está determinada por el desempeño ajustado a los fines y cometidos de la entidad.

La Ley 909 de 2004 establece que los principios que orientan la permanencia en el servicio y de la evaluación del desempeño son: el mérito, fundado en el logro de resultados y realizaciones en el desarrollo y ejercicio de la función pública, así como las nuevas competencias que demande su ejercicio, el cumplimiento cabal de las normas que regula la función pública y las funciones asignadas al empleo, así como colaborar en un ambiente de trabajo en grupo y en defensa permanente del interés público. Cada empleado asume un compromiso con la protección de los derechos, los intereses legales y la libertad de los ciudadanos.

El desempeño laboral de los empleados de carrera debe ser evaluado y calificado con base en parámetros previamente establecidos. E1 resultado de la evaluación será la calificación correspondiente al periodo anual, que deberán incluir dos evaluaciones parciales al año. Sin embargo, si durante este periodo el jefe del organismo recibe información debidamente soportada de que el desempeño laboral de un empleado es deficiente, podrá ordenar por escrito que se le evalúen y califiquen sus servicios de forma inmediata. Sobre la evaluación definitiva del desempeño proceden los recursos de reposición y apelación.

\section{Del retiro de los servidores de carrera}

Como quiera que el sistema de carrera es opuesto al clientelismo corruptor, el nominador no ejerce competencia discrecional sobre el retiro de estos servidores, sino que debe someterse a las causales fijadas en la Ley.

La Ley 909 de 2004 fijó las causales de retiro de los servidores, así: por declaratoria de insubsistencia como consecuencia del resultado no satisfactorio en la evaluación del desempeño laboral, por renuncia regularmente aceptada, por pensión de jubilación, por invalidez absoluta, por edad de retiro forzoso, por destitución como consecuencia de proceso disciplinario, por declaratoria de vacancia en el caso de abandono del cargo, por decisión judicial, por supresión del empleo y por muerte.

La Corte Constitucional afortunadamente declaró inexequible la causal por razones del buen servicio, señalada en el literal C del Artículo 41 de la Ley 909 de 2004, por cuanto en el sistema de carrera el nominador no puede tener discrecionalidad en la facultad de nominación y remoción, como quiera que ella es reglada. E1 retiro de los servidores de carrera está sometido a las causales fijadas en la Ley, y no puede otorgarse facultades generales que puedan generar desviaciones contra los principios rectores de la carrera como el mérito y la igualdad de oportunidades $^{20}$.

\section{Retiro de los provisionales}

La Corte Constitucional ha indicado que los empleados vinculados en provisionalidad gozan de estabilidad relativa en el empleo, en razón a la naturaleza del cargo y el tipo de funciones que desempeñan, de tal suerte que no pueden asimilarse, para efectos de su retiro del

20 CORTE CONSTITUCIONAL. Sentencia C-501 de 2005 M.P. Manuel José Cepeda Espinosa. 
servicio, a un empleado de libre nombramiento y remoción, con la condición que cumplan los requisitos exigidos para el cargo. Considera que pueden ser desvinculados cuando la administración convoque el respectivo concurso de méritos para proveer definitivamente la plaza ${ }^{21}$.

Igualmente, el máximo Tribunal Constitucional exige al nominador motivar el acto administrativo de insubsistencia, en respeto al debido proceso administrativo y de otorgar al empleado el derecho de controvertir la decisión en sede administrativa ${ }^{22}$.

En cambio, el Consejo de Estado ha sostenido que los empleados en provisionalidad no gozan de estabilidad alguna, en razón a que son vinculados a la administración mediante la discrecionalidad del nominador y en consecuencia, pueden ser retirados del servicio discrecionalmente por la administración. El fuero de estabilidad se predica exclusivamente de los empleados escalafonados en carrera, y mal podría aplicarse a provisionales que no se encuentran inscritos en el escalafón de carrera ${ }^{23}$.

En conclusión, los empleados provisionales podrán hacer uso de la Acción de Tutela, como mecanismo transitorio, con la pretensión de ser reintegrados, cuando demuestren vulneración de derechos fundamentales, siempre y cuando el cargo no haya sido provisto de manera definitiva, como resultado del respectivo concurso de méritos.

Esta problemática tiene base en la lentitud en la expedición de normatividad en algunas carreras especiales y en la laxitud dada a los

21 CORTE CONSTITUCIONAL. Sentencias T- 800 de 1998, C- 366 de 1999, C- 109 de 2000, C - 1146 de 2002, C - 793 de 2002, T - 610 de 2003, T- 254 de 2006, T- 432 de 2006 y T - 410 de 2007.

22 CORTE CONSTITUCIONAL. Sentencias T - 225 de 2005, T - 267 de 2005 y T -410 de 2007.

23 CONSEJO DE ESTADO. Sentencias de abril 18 de 2002, rad. 5093-01 y marzo 13 de 2003 rad. 760023-13 de 1998. nominadores en el adelantamiento de los respectivos concursos, por lo que una vez expedidas las normas deberán surtirse los procesos correspondientes sin dilación alguna.

\section{Acto Legislativo 01 de 2008 sobre inscripción extraordinaria o automática en carrera}

En diciembre de 2008 se publicó el texto definitivo del Acto Legislativo 01, mediante el cual se adicionaba al Artículo 125 de la Carta Política un parágrafo que indicaba que durante el tiempo de tres años contados a partir de la vigencia de este acto legislativo, la Comisión Nacional del Servicio Civil implementaría los mecanismos necesarios para la inscripción extraordinaria y sin necesidad de concurso, a los servidores que a la fecha de publicación de la Ley 909 de 2004 estuviesen ocupando cargos de carrera en provisionalidad y que a la fecha de la inscripción se encaran ocupando los mismos cargos de carrera.

Así las cosas, como lo señalamos desde la cátedra y nuestros escritos, este proyecto elevaba a canon constitucional al clientelismo, el favoritismo y el nepotismo, contrariando el sentido del mismo Artículo 125 Constitucional que señala que todos los empleos del Estado son de carrera y echaba a la borda los principios de mérito, igualdad, transparencia y acceso a los cargos y funciones públicas, como quiera que se privilegiaba a quienes de manera discrecional fueron nombrados por clientelismo, el padrinazgo político característico en algunas entidades de la Nación y entidades territoriales, amiguismo o nepotismo, desconociendo a las personas que capacitadas y honestas carecen de influencia para acceder a un cargo público en contravía de los principios democráticos y de justicia mencionados sobre igualdad de oportunidades para ingresar a la Función Pública y el derecho de acceder a tales cargos. Por tanto, en este caso, se privilegiaba a más de 60.000 
provisionales, quienes debían obligatoriamente someterse en igualdad de condiciones con los desempleados mediante concurso de méritos. Así, se premiaba a quienes tienen nexos de amistad o son asiduos con los políticos de turno o altos jerarcas del Estado y se castigaba a quienes careciendo de este tipo de influencias tienen derecho a acceder al desempeño de cargos y funciones públicas, en un país donde el desempleo es uno de los más altos de América Latina, 12\% para el mes de enero de $2010^{24}$.

Tales disposiciones son factor estimulante de la ineficiencia, la ineficacia y la corrupción de la administración. Según la Contraloría General de la República, las cifras de corrupción en el año 2009 alcanzan los 4 billones de pesos en esta vergonzosa materia.

\subsection{Posición de la Procuraduría General de la Nación frente al Acto Legislativo 01 de 2008}

El Procurador General de la Nación, Doctor EDGARDO JOSE MAYA, solicitó en marzo de 2008 al Congreso de la República revisar el proyecto de acto legislativo al considerar que eliminaba las garantías de acceso igualitario a la función pública.

Insistió en que la provisión de cargos de carrera debe ser la consecuencia de la realización de concursos públicos, tal como lo expresa la norma constitucional, la cual es clara en que la provisionalidad es una figura transitoria, y reiteró la jurisprudencia de la Corte Constitucional sobre concursos públicos de carrera y concursos públicos especiales, sobre que el principio democrático de derecho obliga a su realización para el acceso a la función pública, esto es, que exista igualdad de oportunidades

24 DANE. Cifras de Desempleo en Colombia. Bogotá. Enero de 2010. para todos los ciudadanos que aspiren a vincularse al Estado ${ }^{25}$.

Igualmente, consideró que esta iniciativa no puede ir en desmedro de uno de los principios más claros de la Constitución Política, el cual es el de la profesionalización absoluto de la Función Pública, a efectos de erradicar las prácticas inadecuadas como el clientelismo.

El análisis de fondo sobre el contenido de la norma por formulación del cargo por sustitución constitucional contra actos legislativos, consiste en establecer el eje definitorio de la identidad de la Carta Política que se considere vulnerado con la reforma y es a partir del cual se debe hacer el juicio de sustitución.

Para el caso en estudio, el eje definitorio de identidad de la Constitución vulnerado son los principios de igualdad de oportunidades, democracia y el derecho de acceder al desempeño de cargos y funciones públicas, al desconocer que la garantía básica del ingreso a la Función Pública es el mérito. Por tanto, la norma busca legitimar prácticas antidemocráticas como el favoritismo y el clientelismo.

En concepto del 30 de julio de 2009 dirigido a la Corte Constitucional el actual Procurador General, ALEJANDRO ORDOÑEZ MALDONADO, consideró que el Acto Legislativo 01 de 2008 resulta inconstitucional al ser totalmente opuesto con la identidad constitucional en materia de ingreso a los cargos de carrera administrativa, porque dicha provisión tiene que ser el resultado de la demostración, en concursos públicos convocados en igualdad de condiciones, de las calidades de los aspirantes, con la finalidad de garantizar la vigencia de un orden justo dentro de un marco democrático y participativo, en lo que tienen que ver con el derecho fundamental del acceso al desempeño

25 PROCURADURIA GENERAL DE LA NACIÓN. Concepto del 27 de marzo de 2008. 
de cargos públicos de carrera, como expresión de libertad de escoger profesión u oficio ${ }^{26}$.

Así las cosas, para que una reforma para la provisión de cargos públicos como la establecida en el acto legislativo cuestionado resulte viable, tiene que reformarse el orden constitucional en asuntos como la vigencia de un orden justo, la paz, la participación y la democracia. En ese contexto, la sociedad haría la política de otra manera diferente a un derecho fundamental; por ejemplo, mediante la "democracia gremial", donde, a través de la agremiación y según el poder político que tuviera la misma, se accedería a la vida pública. En este sentido, los cargos públicos serían ocupados, no por mérito, sino según la postulación que hicieran gremios como partidos políticos, grupos económicos, religiosos, académicos, sindicales, etc.

En este orden de ideas, consideró el jefe supremo del Ministerio Público que el Congreso de la República al tramitar y aprobar el Acto Legislativo 01 de 2008, se extralimitó en el ejercicio de sus funciones para reformar la Carta Política, ya que con la inscripción automática en los cargos de carrera sin necesidad de concurso público, a manera de concesión graciosa presentada como derecho, produjo una sustitución de la misma de carácter parcial en el tema relacionado con la provisión definitiva de los cargos de carrera administrativa mediante el mérito, como expresión de la garantía de la vigencia de un orden justo en materia política y laboral, incluyendo la liberta de escoger profesión u oficio.

De otro lado, considera que no hubo reforma constitucional sino desviación de poder por parte del Congreso de la República, por aprobar algo que no tiene relación con la Constitución, desde el punto de vista de su legitimidad, utilizando para ello la competencia reformadora de

PROCURADURIA GENERAL DE LA NACIÓN. Concepto No. 4827 del 30 de julio de 2009. la Carta, constitucionalizando un interés particular en materia laboral, en contra del interés general en lo que tiene que ver, de modo directo, con la identidad política, económica y social de la Nación e indirectamente con la eficacia en el cumplimiento de los fines del Estado.

En este caso, se observa que el proceder del legislador está inmerso en la problemática de tratar las constituciones como leyes, para instrumentalizarlas en función de intereses particulares, lo cual desborda y desnaturaliza la concepción y razón de ser de las Cartas Políticas como contratos fundacionales para conducir a las sociedades, en todos los tiempos, bajo la guía de valores y principios fundamentales que se constituyen en la identidad de las naciones, según su voluntad de organización política.

Los planteamientos anteriores fueron acogidos en gran medida por la Corte Constitucional posteriormente en la sentencia C - 588 de 2009 , que declaró la inexequibilidad del Acto Legislativo 01 de 2008, con ponencia del magistrado GABRIEL EDUARDO MENDOZA MARTELO.

\section{Declaratoria de inexequibilidad por la Corte Constitucional del Acto Legislativo}

Después de haber transcurrido seis meses desde la adopción de la decisión sobre inexequibilidad del Acto Legislativo 01 de 2008, por parte de la Corte Constitucional, en la página web de ese Tribunal solo aparecía el comunicado de prensa que daba cuenta de la misma.

En ese informe se indicaba que la Corte Constitucional respecto a la cláusula de sustitución, reiteró la tesis según la cual el constituyente derivado tiene competencia para reformar la Constitución, más no para sustituirla, considerando que cuando exista sustitución o cambio de un eje definitorio sobre la identidad de nuestro Estado Social de Derecho, implica un 
vicio de competencia por ejercicio excesivo del poder reforma.

La Corte determinó que el parágrafo transitorio agregado en el Artículo 1 del Acto Legislativo 01 de 2008 vulneraba el Artículo 125 Constitucional que establece como postulado general la carrera administrativa, el mérito y el concurso para ingresar o ascender en la misma, el parágrafo transitorio creaba un derecho de inscripción extraordinaria en carrera administrativa fundado solo en la experiencia y prescinde del concurso público. Tal disposición beneficiaba quienes ocuparan cargos de carrera vacantes en calidad de provisionales o por encargo.

El máximo Tribunal Jurisdiccional planteó que la premisa mayor se encuentra en el Artículo 125 citado, al ser el sistema de carrera el instrumento óptimo para la provisión de empleos públicos y así mismo, el criterio del mérito y el concurso público que guían el sistema de carrera. Además relaciona el sistema con los fines del Estado fijados en el Artículo 2 Constitucional, con los derechos de los ciudadanos a acceder a cargos públicos, señalado en el numeral 7 del Artículo 40, los derechos de los trabajadores como la estabilidad, consagrados en el Artículo 53 Constitucional y con el derecho a la igualdad.

La Corte señala que efectuado el cotejo entre la premisa mayor y el texto del Acto Legislativo 01 de 2008, encontró oposición entre ella y la norma demandada, así:

El sistema de carrera, el mérito y el concurso no son compatibles con la inscripción automática, al fundarse en la experiencia y prescindir del concurso.

Tampoco existe compatibilidad entre el ingreso automático y el derecho a acceder a cargos y funciones públicas, pues quien no sea provisional o encargado no podrá aspirar a los cargos de carrera definitivamente vacantes y por tanto, quienes no tenga tales calidades se les impide los beneficios de carrera, luego el Artículo 53 superior no rige para ellos.

La incompatibilidad entre el derecho a la igualdad y la inscripción extraordinaria en carrera es ostensible, por cuanto beneficia solo a los provisionales o a los encargados en cargos de carrera, lo cual afecta la igualdad de oportunidades, creando un privilegio de ingreso automático o inscripción extraordinaria en carrera.

Para la Corte, demostrada la oposición comporta una sustitución de la Carta, por cuanto produce un quebrantamiento de uno de sus ejes definitorios de la identidad de nuestro Estado Social de Derecho, que reevidencia mediante la introducción de excepciones a cada uno de los elementos integrados en la premisa mayor $\mathrm{y}$, además, porque, en la práctica, suspende la Constitución con el eje definitorio construido a partir de la carrera administrativa y de sus relaciones con otros contenidos constitucionales.

Igualmente, la Corte consideró que se vulneraba el principio de separación de poderes con el acto cuestionado, en razón a que otorgaba a la Comisión Nacional del Servicio Civil facultades de reglamentación sobre inscripción automática en carrera, pues de conformidad con el Artículo 125 Constitucional, todo 1o que trate sobre el sistema de carrera es materia reservada de la ley, y por tanto, excluye la regulación por reglamento y quedaría la Corte Constitucional de efectuar control sobre los actos de carrera administrativa, al sustraer al Congreso de esta facultad.

Por esas razones, la Corte Constitucional declaró inexequible el Acto Legislativo 01 de 2008.

Los Magistrados MAURICIO GONZALEZ CUERVO, JORGE IGNACIO PRETELT CHALJUB, NILSON PINILLA PINILLA y HUMBERTO SIERRA PORTO, según el aviso, salvaron su voto. 


\section{CONCLUSIONES}

El sistema de carrera administrativa busca asegurar el mérito como eje central de la vinculación, permanencia y ascenso en el empleo público, por lo que el Estado debería ampliar su cobertura a ciertos cargos de dirección, con la finalidad de avanzar en el logro de la eficacia, eficiencia y progreso en la prestación de los servicios públicos y de los cometidos estatales.

La corrupción y la ineficiencia de la administración tienen origen en el carácter parcializado y poco cualificado en el ingreso y desempeño de quienes prestan sus servicios al Estado, especialmente en cargos de gerencia pública y dirección intermedia.

La ley debe ser más rigurosa sobre sanciones a los nominadores que dilaten, obstaculicen o vulneren dolosamente los procesos de carrera administrativa y de meritocracia, para hacer efectividad la normatividad legal y reglamentaria sobre el régimen.

E1 Acto Legislativo 01 de 2008, sobre inscripción automática a empleados en provisionalidad sin concurso de méritos, por el simple paso del tiempo, sustituía un eje definitorio de la identidad de la Carta Política como lo es el mérito, eje central del ingreso a la función pública, pues como lo señala el Artículo 125 Constitucional, todos los empleos del Estado son de carrera y los que la ley no haya fijado el sistema de ingreso debe hacerse mediante concurso. Así, la sustitución de un eje definitorio de la Constitución es competencia del constituyente primario y no del Congreso de la República, que obra como constituyente derivado, el cual solo tiene facultades de reformar la Carta y no de sustituirla.

El ingreso automático o inscripción extraordinaria en Carrera Administrativa desnaturalizaba el sistema mismo, pues se dejan de lado el mérito y las capacidades, permitiendo que la discrecionabilidad de los nominadores rigiera en el sistema e impidiendo que todos aquellos que crean tener las condiciones para desempeñar un empleo de esta naturaleza, tengan la oportunidad de acceder a ellos, simplemente por que no hay un mecanismo que permita la evaluación de sus méritos y capacidades.

\section{BIBLIOGRAFÍA}

Collazos Álvarez, Augusto. "¿Por qué no funciona el sistema de Carrera Administrativa?". En: Revista Administración y Desarrollo. Escuela Superior de Administración Pública. No. 42. $2^{\circ}$ Semestre de 2004. Bogotá.

CONSEJO DE ESTADO. Sentencia del 18 abril de 2002. Rad. 5093-01.

CONSEJO DE ESTADO. Sentencia del 13 marzo de 2003. Rad. 7600-23-13 de 1998.

CORTE CONSTITUCIONAL. Sentencia C-109 de 2000.

CORTE CONSTITUCIONAL. Sentencia C-195 de 1994. M.P. Vladimiro Naranjo Mesa.

CORTE CONSTITUCIONAL. Sentencia C-366 de 1999.

CORTE CONSTITUCIONAL. Sentencia C-372 de 1999. M. P. José Gregorio Hernández Galindo.

CORTE CONSTITUCIONAL. Sentencia C-501 de 2005 M.P. Manuel José Cepeda Espinosa.

CORTE CONSTITUCIONAL. Sentencia C-563 de 2000. M. P. Fabio Morón Díaz.

CORTE CONSTITUCIONAL. Sentencia C-733 de 2005. M. P. Clara Inés Vargas Hernández.

CORTE CONSTITUCIONAL. Sentencia C-793 de 2002.

CORTE CONSTITUCIONAL. Sentencia C-1146 de 2002. 
CORTE CONSTITUCIONAL. Sentencia SU-257 de 1999. M. P. José Gregorio Hernández.

CORTE CONSTITUCIONAL. Sentencia T-225 de 2005.

CORTE CONSTITUCIONAL. Sentencia T-254 de 2006.

CORTE CONSTITUCIONAL. Sentencia T-256 de 1995. M. P. Alejandro Martínez C.

CORTE CONSTITUCIONAL. Sentencia T-267 de 2005.

CORTE CONSTITUCIONAL. Sentencia T-410 de 2007.

CORTE CONSTITUCIONAL. Sentencia T-432 de 2006.

CORTE CONSTITUCIONAL. Sentencia T-610 de 2003.

CORTE CONSTITUCIONAL. Sentencia T-720 de 2008. M. P. Jaime Córdoba. T.

CORTE CONSTITUCIONAL. Sentencia T-800 de 1998.

CONGRESO DE LA REPUBLICA. Gaceta No. 232 de 2003.

DANE. Cifras de Desempleo en Colombia. Bogotá. Enero de 2010.

Fernández Naranjo, Jaime. El Manual de la Carrera Administrativa. Ultragraf Editores. Cali. 1994.

Giraldo Saavedra, Alberto. "Competencias Laborales y Carrera Administrativa". En: Revista Administración y Desarrollo. Escuela Superior de Administración Pública. No. 42. $2^{\circ}$ Semestre de 2004. Bogotá.

GONZÁLEZ CAMPOS, Federico. Jurisprudencia de la Tutela. Señal Editora. Bogotá, 1994.

González García, Emilio. "La Carrera Administrativa en la modernización estatal". En:
Revista Administración y Desarrollo. Escuela Superior de Administración Pública. No. 42. $2^{\circ}$ Semestre de 2004. Bogotá.

González Salas, Edgar. "La Carrera Administrativa: experiencias y perspectivas". En: Revista Administración y Desarrollo. Escuela Superior de Administración Pública. No. $42.2^{\circ}$ Semestre de 2004. Bogotá.

Grillo Rubiano, Fernando. "Situación de la Carrera Administrativa en Colombia." En: Revista Administración y Desarrollo. Escuela Superior de Administración Pública. No. 42. $2^{\circ}$ Semestre de 2004. Bogotá.

http://cuadernosadministracion.javeriana. edu.co/pdfs/3_28.pdf.

OBANDO GARRIDO, José María. Derecho Administrativo Laboral. Ediciones Doctrina y Ley. Bogotá. 2002.

PARRA GUTIERREZ, William René. Empleo Público, Gerencia Pública y Carrera Administrativa. Ibáñez. Bogotá. 2005.

PENAGOS VARGAS, Gustavo. Nombramientos e insubsistencias discrecionales, partidistas o arbitrarios. Ediciones Doctrina y Ley. Bogotá. 1998.

El Acto Administrativo. Tomos I, II y III. Ediciones Librería del Profesional. Bogotá. 1993.

PINZÓN ARIZA, Blanca Ligia. La tutela en la Carrera Administrativa. Librería del Profesional. Bogotá. 1998.

PROCURADURIA GENERAL DE LA NACION. Concepto del 27 de marzo de 2008 Concepto No. 4827 del 30 de julio de 2009.

Los Actos de intervención preventiva en materia laboral. Instituto de Estudios del Ministerio Público. Bogotá. 2007.

Puentes González, Germán. "Carrera Administrativa y Democracia". En: Revista 
Administración y Desarrollo. Escuela Superior de Administración Pública. No. 42. $2^{\circ}$ Semestre de 2004. Bogotá.

RINCON PACHON, Jairo. Teoría de la Administración Pública. Librería del Profesional. Bogotá. 1996.

Rodríguez Bernal, Adolfo. "Políticas de gestión pública y reforma Estatal". En: Revista Administración y Desarrollo. Escuela Superior de Administración Pública. No. 42. $2^{\circ}$ Semestre de 2004. Bogotá.
VANEGAS CASTELLANOS, Alfonso. Teoría y Práctica de la Acción de Tutela. Editemas AVC. Bogotá. 1996.

VILLEGAS ARBELAEZ, Jairo. Derecho Administrativo Laboral. Legis. Bogotá. $5^{\text {a }}$ Edición. 2002.

YOUNES MORENO, Diego. Derecho Administrativo Laboral. Temis. Bogotá. 2005.

Las Reformas del Estado y de la Administración Pública. Temis. Bogotá. 1992. 
